\title{
Serial learning in a continuous serial list'
}

KAY BRECKENRIDGE, DAVID T. HAKES AND ROBERT K. YOUNG

UNIVERSITY OF TEXAS

\begin{abstract}
Learning of a continuous serial list with no intertrial interval (ITI) and no starting symbol was compared with learning of a standard serial list. As in a previous study by Lippman \& Denny (1964), it was found that the continuous list was learned significantly more slowly and yielded a flattened serial position curve. There was a marked tendency for Ss in the continuous-list condition to respond correctly most often to the item which appeared second. When the item on which each $S$ in this condition performed best was placed in the first serial position, a typical serial position curve was reinstated with some diminution of the recency effect. It was concluded that in the absence of explicit serial position cues Ss tend to provide their own.
\end{abstract}

\section{Problem}

Lippman \& Denny (1964) have recently reported an experiment on the effects of the intertrial interval (ITI) on serial learning. In a condition in which the list contained neither an ITI nor a starting symbol (i. e., a continuous list), learning was found to be more difficult than under standard serial learning conditions. The serial position curve for this group, plotted from the item which appeared first on the first trial (the Actual First), showed no recency effect and a diminished primacy effect. The primacy effect was further diminished in a condition involving a continuous list which was preceded on the first trial by four dummy items.

For both of these conditions, when the serial position curve was plotted from the item which each $\mathrm{S}$ gave correctly most often (the Objective First), a typical serial position curve appeared, though somewhat less bowed than under control conditions. From these results, Lippman \& Denny concluded that even in the absence of explicit serial position cues Ss tend to select an item within the list as a cue for position learning. They further suggested that seeing an item first on even one trial makes that item more discriminable and, hence, more likely to be used as a cue. This would account for the observe primacy effect in the Actual First position curve for the continuous-list group. It is interesting to note that it was the item following the Actual First item which was given correctly most often by this group, suggesting that the first item served the function of a starting symbol.

These results have considerable significance for studies which have suggested that Ss form inter-item associations in the absence of position cues. The studies of the variable-starting-point serial list (e. g., Ebenholtz, 1963; Keppe1, 1964) may require reinterpretation if Ss do create their own position cues in the absence of explicit ones.
The strength. of Lippman \& Denny's conclusion is somewhat vitiated, however, by the fact that all Ss in all conditions learned the same serial list. Thus position effects were completely confounded with item effects. Some effects of this confounding are evident in the serial position curves which they present, all curves plotted from the Actual Firstitem showing peaks on the same items. Thus it is possible that the selection of the Actual Firstitem as a position cue which was noted for the continuous-list group was a function of that item's being easier rather than of its being first.

The present experiment permits further evaluation of Lippman \& Denny's results in a design in which position effects can be assessed independently of item effects.

\section{Method}

Two main conditions were employed: an Experimental condition in which Ss learned a continuous serial list with no ITI and no starting symbol and a Control condition in which Ss learned a standard serial list with a 6-sec. ITI and a starting symbol of "XXX." The lists used were formed from two sets of 10 two-syllable adjectives from the Melton \& Safier lists (Hilgard, 1951), selected for low formal and meaningful similarity. Two random orders of each item set were prepared, yielding * four lists within each condition. Equal numbers of Ss in the Experimental group were started on each item in the continuous list. The lists were presented on a memory drum at a $2-\mathrm{sec}$. rate. Learning was continued to a criterion of 10 consecutive correct responses (i. e., one perfect trial) or for a maximum of 50 trials.

Forty Ss from introductory psychology classes served and were assigned to conditions randomly with the restrictions that equal numbers served in each condition and learned each of the four lists. None had served previously in a verbal learning experiment.

\section{Hesults and Discussion}

The Experimental and Control groups required 24.60 and 15.10 trials, respectively, to reach criterion. In the analysis of trials to criterion, Conditions yielded a highly significant effect $(F=8.64, d f=1 / 32, p<.01)$. No other effect, Lists, Item Orders, or any of the interactions, reached significance. This result is consistent with that obtained by Lippman \& Denny in indicating that the absence of the ITI and starting symbol increases the difficulty of serial learning.

The results of the serial position analyses are presented in Fig. 1. The Control group yielded the typical bowed serial position curve. The curve for the Experimental group, plotted from the Actual First item, reveals an effect similar to that obtained by Lippman \& Denny: 


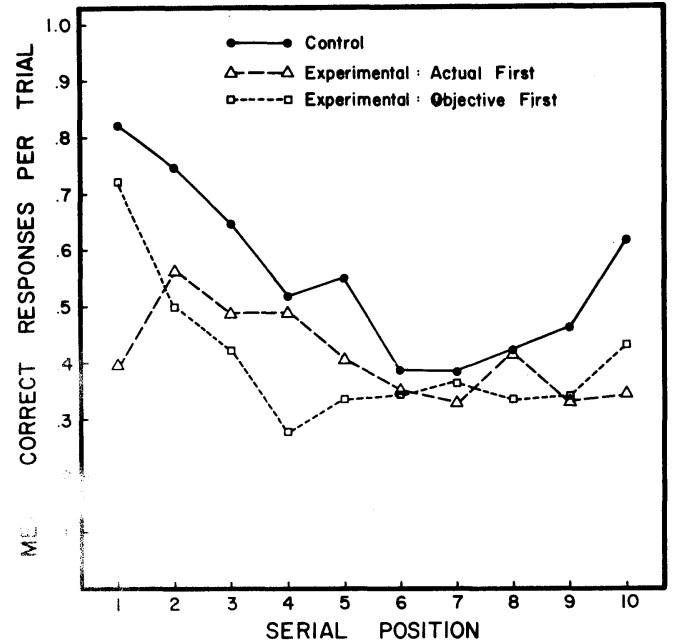

Fig. 1. Jean numbers of correct responses per trial at each serial pusition for the Control group and the Actual First and objective First analyses (see text) for the Experimental group.

the recency effect is eliminated and the primacy effect reduced. In addition, the second item is given correctly most often. An analysis of the linear trend component of this curve indicates a significant trend $(F=14.20$, $\mathrm{df}=1 / 19, \mathrm{p}<.01$ ), indicating that items in successive positions following the Actual First item became more difficult.

No significant difference in linear trend between the Actual First and Control conditions was noted $(F=3.50$, $\mathrm{df}=1 / 32, \mathrm{p}>.05)$. These conditions do differ in quadratic trend $(\mathrm{F}=17.25, \mathrm{df}=1 / 32, \mathrm{p}<.01)$. Thus, despite considerable flattening of the position curve, resulting primarily from the elimination of recency effects, the primacy effect noted by Lippman \& Denny is present in these ata. Seven of the $20 \mathrm{Ss}$ in the Experimental group responded correctly most often to the item immediately following the Actual Firstitem. If the most-oftencorrect item were a randomly distributed event, it would be expected that two Ss would give that item. Thus the obtained result represents a highly significant departure from randomness $(p<.003)$. This effect cannot be attributed to differential item difficulty and, therefore, strongly supports Lippman \& Denny's conclusion that Ss tend to select the Actual Firstitem as a position cue.

The Experimental group's serial position curve was also determined using the item to which each $\mathrm{S}$ responded correctly most often as the item in the first serial position (i. e., Objective First). The results of this. analysis are presented in Fig. 1. It is apparent that both prim cy and recency effects are present, though not to the xtent in the Control group. Linear trend differs between the Experimental group's Objective
First data and that of the Control group $(F=33.00$, $\mathrm{df}=1 / 32, \mathrm{p}<01)$. The Conditions $\mathrm{x}$ Quadratic Trend interaction is not significant $(F<1)$. These results may be attributed to the relatively flatter position curve and less marked recency effect for the Objective First data and are quite similar to the results of Lippman \& Denny's Objective First analysis.

Since the results of the Objective First analyses could have been produced by the first item alone, and thus be artifacts of placing the most-often-correct item in first position, the data were also analyzed omitting the first item for both Experimental and Control groups. The Objective First data still reveal a significant quadratic trend $(F=8.07, \mathrm{df}=1 / 19, \mathrm{p}<.05)$, indicating that even without the first item the position curve is bowed. In addition, the Conditions $x$ Quadratic Trend interaction is not significant $(F=2.59, \mathrm{df}=1 / 32)$. Thus, the conclusions are not modified by omitting the first item from the analyses.

The present results lend considerable support to Lippman \& Denny's conclusions. In the absence of explicit position cues, the typical serial position effect is diminished but not eliminated. There appears to be a tendency for $\mathrm{S}$ to select some item within the list as a position cue and for the item selected to be the one appearing first on the first trial. While the earlier results could be interpreted as resulting from differential item difficulty, the present results do not allow such an interpretation. The tendency to select the firstappearing item as a cue appears to result from that item's unique position on the first trial.

That the typical serial position curve is not completely reinstated by the Objective First analysis suggests that the subject-supplied position cues cannot be used as effectively as explicitly-provided cues. But the apparent tendency of Ss to supply position cues indicates that results such as those reported by Keppel (1964) which appear to indicate differences in retroactive interference as a function of the presence or absence of explicit position cues must be interpreted with caution.

\section{References}

Ebenholtz, S. M. Serial learning: Position learning and sequential associations. J. exp. Psychol., 1963, 66, 353-362.

Hilgard, E. R. Methods and procedures in the study of learning. In S. S. Stevens (Ed.), Handbook of experimental psychology. New York: Wiley, 1951.

Keppel, G. Retroactive inhibition of serial lists as a function of the presence or absence of positional cues. J. verbal Learn. verbal Behav., 1964, 3, 511-517.

Lippman, L. G., \& Denny, M. R. Serial position effect as a function of intertrial interval. J. verbal Learn. verbal Behav., 1964, $3,496-501$.

\section{Note}

1. This research was supported, in part, by a grant from the Nationa! Science Foundation (GB-979) to Robert K. Young and David T. Hakes. 